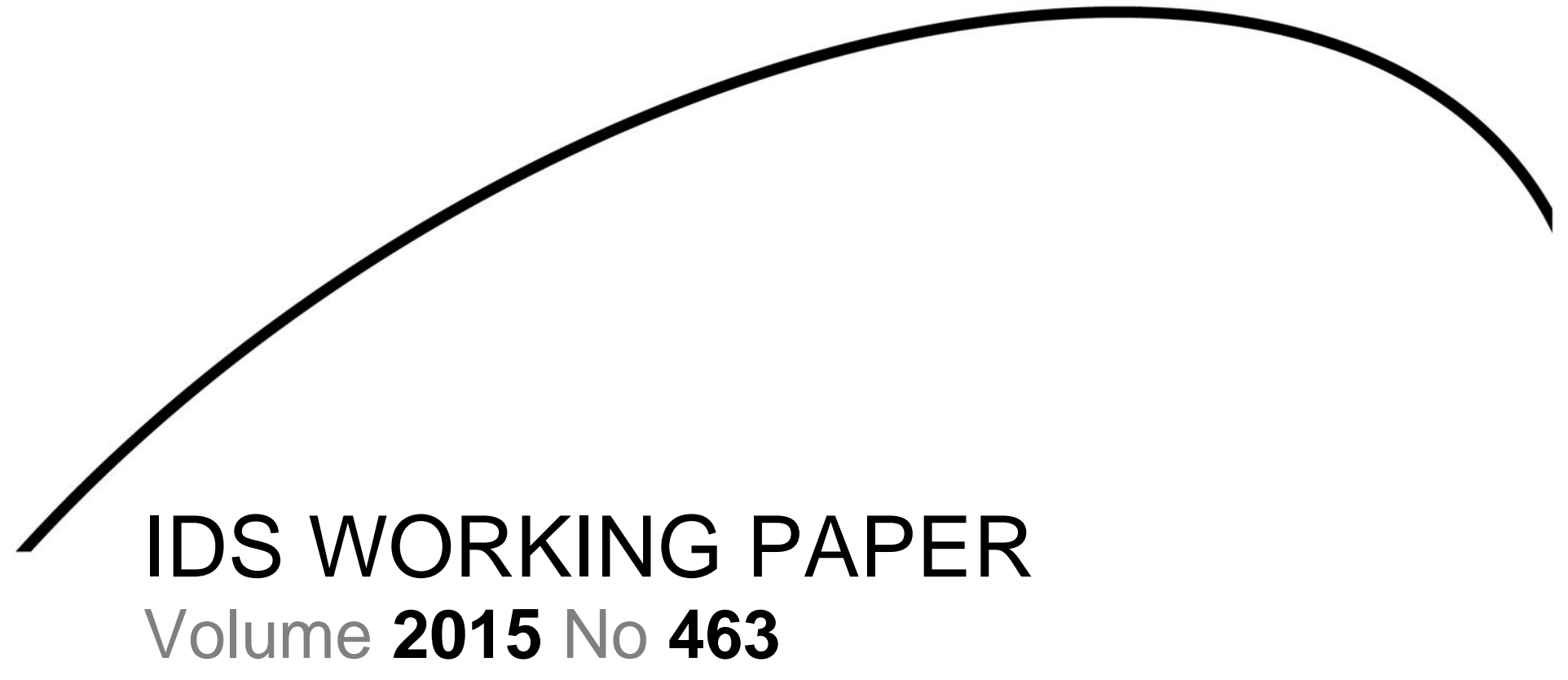

\title{
Age and Gender Effects on Time Discounting in a Large Scale Cash Transfer Programme
}

Bruno Martorano, Sudhanshu Handa, Carolyn Halpern, Audrey Pettifor and Harsha Thirumurthy

October 2015 
Age and Gender Effects on Time Discounting in a Large Scale Cash Transfer Programme

Bruno Martorano, Sudhanshu Handa, Carolyn Halpern, Audrey Pettifor, and Harsha Thirumurthy

IDS Working Paper 463

(C) Institute of Development Studies 2015

ISSN: 2040-0209 ISBN: 978-1-78118-274-1

A catalogue record for this publication is available from the British Library.

All rights reserved. Reproduction, copy, transmission, or translation of any part of this publication may be made only under the following conditions:

- with the prior permission of the publisher; or

- with a licence from the Copyright Licensing Agency Ltd., 90 Tottenham Court Road, London W1P 9HE, UK,

or from another national licensing agency; or

- under the terms set out below.

This publication is copyright, but may be reproduced by any method without fee for teaching or nonprofit purposes, but not for resale. Formal permission is required for all such uses, but normally will be granted immediately. For copying in any other circumstances, or for re-use in other publications, or for translation or adaptation, prior written permission must be obtained from the publisher and a fee may be payable.

Available from:

Communications and Engagement Unit, Institute of Development Studies, Brighton BN1 9RE, UK

Tel: +44 (0) 1273915637

E-mail: bookshop@ids.ac.uk

Web: www.ids.ac.uk/publications

IDS is a charitable company limited by guarantee and registered in England (No. 877338) 


\title{
Age and Gender Effects on Time Discounting in a Large Scale Cash Transfer Programme
}

\author{
Bruno Martorano, Sudhanshu Handa, Carolyn Halpern, Audrey Pettifor \\ and Harsha Thirumurthy
}

\begin{abstract}
Summary
Inter-temporal choice represents one of the most fascinating topics in economics. Understanding its determinants can provide vital insight into decisions ranging from savings and financial investment to smoking, obesity and human capital accumulation. This article contributes to a growing literature that seeks to identify the determinants of inter-temporal choice. We explore the role of income shocks, age and gender on time discounting using evaluation data from the Government of Kenya's largest social protection programme, the Kenya Cash Transfer for Orphans and Vulnerable Children (CT-OVC). Study participants were randomised to treatment and control arms in 2007 and data on time discounting was collected on participants four years after programme inception. Our paper confirms that middle-aged groups are more patient than younger and older adults. In contrast to the empirical evidence, females are less patient than males and this situation is more evident during young and adult life. Males lose their patient during old age. Considering the impact of the programme, the average treatment effect of the programme on time discounting is negligible. However, it varies strongly with age of the recipient, with large and statistically significant effects among prime-age recipients and no effects on younger or older recipients. Moreover, these results are stronger for females than males, an important result given that over 60 per cent of recipients in target households are females.
\end{abstract}

Keywords: Time preference; age effects; gender differences; cash transfers; Kenya.

Bruno Martorano is a Postdoctoral Fellow at the Institute of Development Studies and a Research Associate at Consortium pour la recherche économique et sociale (CRES) in Dakar, Sénégal. Previously, Bruno has worked at the UNICEF Office of Research in Florence and the University of Florence, and has held consultancies for the University of North Carolina - Chapel Hill; UNCTAD; UNU-WIDER and the World Bank.

Sudhanshu Handa is currently on leave from the University of North Carolina (Carolina Population Centre) and is serving as Chief of Social \& Economic Policy at UNICEF's Office of Research-Innocenti, Florence, Italy.

Carolyn Halpern is a Professor at the University of North Carolina (Carolina Population Centre). She is a developmental psychologist and Deputy Director/co-investigator of the Waves IV and V Add Health program project.

Audrey Pettifor is an Associate Professor in the Department of Epidemiology at the University of North Carolina and a faculty fellow at the Carolina Population Center.

Harsha Thirumurthy is an Associate Professor of Health Economics in the Department of Health Policy and Management and Gillings School of Global Public Health at the University of North Carolina. He is also a Faculty Fellow at the Carolina Population Center. 


\section{Contents}

Summary, keywords and author notes $\quad 4$

Acknowledgements and acronyms $\quad 5$

Introduction $\quad 6$

1 The Kenya cash transfer programmes for orphans and vulnerable children

2 Evaluation design, data and descriptive statistics 8

2.1 Evaluation design 8

$\begin{array}{ll}2.2 & \text { Attrition } \\ & 9\end{array}$

2.3 Baseline balance 9

$\begin{array}{lll}2.4 & \text { Descriptive statistics } & 10\end{array}$

3 The impact of the programme on time discounting 14

$\begin{array}{lll}3.1 & \text { The empirical strategy } & 14\end{array}$

3.2 The impact of the programme on time discounting: full sample 15

$\begin{array}{ll}\text { 3.3 The impact of the programme on time discounting across age groups } & 16\end{array}$

3.4 The impact of the programme on time discounting by ages and gender 34

4 Conclusion $\quad 21$

Annex 1 Probit estimates of probability of being in treatment group 22

$\begin{array}{ll}\text { Annex } 2 \text { Distribution of probability scores } & 23\end{array}$

$\begin{array}{ll}\text { References } & 24\end{array}$

\section{Figures}

Figure 2.1

Figure 2.2

Figure 2.3

Figure 2.4

Figure 2.5

Figure 2.6

Figure 2.7

\section{Tables}

Table 2.1

Table 2.2

Table 3.1

Table 3.2

Table 3.3

Table 3.4

Table 3.5

Table 3.6

Table 3.7

Table 3.8
Individual switching points (IES)

Per cent who will wait one month by future value

Impatience by age

Impatience by age and sex

Impatience by age (local polynomial fit)

Impatience by age: female (local polynomial fit)

Impatience by age: male (local polynomial fit)

Household characteristics by wave and intervention status in the CT-OVC Evaluation Sample

Mean differences in per cent willing to wait by study arm and amount 13

Mean characteristics of respondents of behavioural module 15

Determinants of time discounting with inverse probability weights $\quad 15$

Determinants of time discounting with inverse probability weights:

people aged less than 25 years old

Determinants of time discounting with inverse probability weights:

people aged 25-59 years old

17

Determinants of time discounting with inverse probability weights:

people aged more than 59 years old

Determinants of time discounting with inverse probability weights:

males

Determinants of time discounting with inverse probability weights:

females

Mean differences in effects derived from coefficients in Table 3.7

(percentage points) 


\section{Acknowledgements}

The authors would like to thank Professor Patricia Justino, Conflict and Violence Cluster Leader at the Institute of Development Studies, and Marco Sanfilippo, Assistant Professor at the Institute of Development Policy and Management at the University of Antwerp, for their comments and feedback on this paper.

\section{Acronyms}

$\begin{array}{ll}\text { CT-OVC } & \text { Cash Transfer for Orphans and Vulnerable Children } \\ \text { DHS } & \text { Demographic and Health Surveys } \\ \text { IPW } & \text { Inverse probability weights } \\ \text { MICS } & \text { Multiple Indicator Cluster Surveys } \\ \text { OLS regression } & \text { Ordinary Least Squares regression } \\ \text { OPM } & \text { Oxford Policy Management } \\ \text { OVC } & \text { Orphan or vulnerable child } \\ \text { UNC IRB } & \text { University of North Carolina Institutional Review Board } \\ \text { UNICEF } & \text { United Nations Children's Fund }\end{array}$




\section{Introduction}

Time preference, the disposition of individuals to delay gratification, has long captured the interest of social scientists due to its perceived importance in determining a wide range of behaviours, from risky sex to savings and investment to exercise and diet, with associated implications for the health and financial wellbeing of individuals and society. In economics, discussions about time preference can be traced back to models of savings, growth and development (Rae 1905; Samuelson 1937) and is even mentioned by Adam Smith in The Wealth of Nations (Smith 1776). Recently economists have begun to use both laboratory and small-scale field experiments to understand the determinants of time preference and the extent to which time preference affects decision-making in financial and other spheres (Akerlund et al 2014; Burks et al 2009; Carvalho et al 2014; Chang et al 2009; Meier and Sprenger 2010; Khwaja, et al 2007). In this article, we take a different approach and report on the determinants of inter-temporal choice from a large-scale field survey that was implemented to evaluate the Government of Kenya's largest social protection programme, the Cash Transfer for Orphans and Vulnerable Children (CT-OVC).

Individuals display significant variation in the weight they place on present versus future consumption and so understanding the role of demographic factors, particularly age, in determining inter-temporal choice is a key issue in the literature in this area (Bradford et al 2014). Most studies argue that younger people are more impatient than adults (e.g Green et al 1999), with explanations about the myopia of youth related to their impulsivity (Whelan and McHugh 2009), their inability to make plans beyond today (Greene 1986) and their inability to foresee the future consequences of their actions (Grisso et al 2003). The contribution coming from other disciplines such as biology or neuro-economics enrich the explanations about preferences across the different age groups. According to Steinberg et al (2009: 40), the actions of younger people 'are mediated by a "socioemotional" network'. People become more patient as they get older. They learn to control their impulses because their actions 'are [now mainly] mediated by a "cognitive control" network' (Steinberg et al, 2009: 40).

Moreover, life events and experiences increase the salience and concreteness of people and shift their orientation from a short to a long-term perspective (Liu and Aaker 2007).

Nonetheless, some authors argue that the relationship between age and the discount rate is not linear and that people in the middle-aged group are not only more patient than youths but they are also more patient than older adults (see Read and Read 2004; Chu et al 2008). Indeed, Sozou and Seymour (2003) argue that the transition to old age pushes up discount rate due to worsening health conditions and the decline in human fertility. Similarly, Trostel and Taylor (2001) explain that the elderly are more impatient because they have few years to live and so they feel more pressure to get satisfaction as soon as possible.

Beyond age, a number of studies also focus on gender differences in time preferences. Almas et al. (2012) report no gender differences in a sample of Norwegian adolescents while Dittrich and Leipold (2014: 414) report that females are more willing to delay gratification than males in Germany due to their ability for self-regulation, created in part because 'women spend more time in child care which requires them to delay their own gratification in order to put infants' needs ahead of their own and which further requires them to resist distractions that separated them from their infants'. Bauer and Chytilová (2013) confirm that females are more patient than males using experimental data from Indian villages. They also refer to the link between women's patience and their child rearing, proposing that the presence of children in the household pushes mothers to delay present gratification and to care more about the future. Ashraf et al (2006) report that Filipino females are more patient than males and tend to be more dedicated to household savings while Ashrsaf (2009) confirms that females maintain control over household finances in the Philippines, which increases their responsibility for household living conditions and supports forward-looking behaviours. 
Following this literature the present article explores the role of age, gender and income shocks (in the form of receipt of the CT-OVC benefit) on time discounting. In particular, our work has two specific goals: we assess whether there are systematic differences in time discounting by age and gender, and then we explore heterogeneous programme effects by these characteristics. To do this - as explained above - we use experimental data collected as part of the impact evaluation of the Government of Kenya's Cash Transfer for Orphans and Vulnerable Children (CT-OVC), an unconditional cash transfer programme that reaches over 150,000 households across the country. We find that middle-aged individuals are more patient than younger and older adults, and in contrast to most of the previous evidence, females are less patient than males, with this gender difference particularly strong at younger ages. Our results also show that an unconditional cash transfer can affect inter-temporal choice, but the impacts vary strongly by age and gender. In particular, we find large and statistically significant effects among prime-age recipients and no effects on younger or older recipients, and programme impacts are stronger for females than males, an important result given that over 60 per cent of recipients in target households are females.

This paper makes substantive as well as methodological contributions. First, data is taken from a large-scale impact evaluation of an actual government cash transfer programme, the largest social protection programme in Kenya today, implying a high degree of external validity as most cash transfer programmes in Africa are unconditional and are similar to the Kenyan programme in terms of target group and design. Second, the paper adds new knowledge on the gender and age differences in time discounting. In addition, measuring the impact of a cash transfer programme on outcomes such as inter-temporal choice is quite new and we are aware of only two other studies along the same vein. Handa et al (2013) show that a national cash transfer programme in Zambia increases the propensity of poor participants to wait for future money, while Rubalcava et al (2009) report that Mexico's PROGRESA programme promotes forward looking decision-making in recipient households headed by couples but not those headed by single females or single males. Finally, this paper is fundamentally different to the majority of work in this area in that it implements relatively simple questions, all hypothetical, in the context of a large multi-topic household survey. In a companion paper we report on the performance of these measures (Handa et al 2014) and show that inconsistencies are remarkably low given the literacy and overall poverty level of the target group, and that measurement error is thus likely to be no worse than questions on income, consumption and labour supply that are now routine in multi-topic surveys such as the Demographic and Health Surveys (DHS), Multiple Indicator Cluster Surveys (MICS) and Living Standards Measurement Surveys.

This paper is structured in the following way: Section 1 describes the Kenya Cash Transfer Programme for Orphans and Vulnerable Children; Section 2 discusses the data and empirical strategy; Section 3 reports the results of our analysis; and finally Section 4 concludes. 


\section{The Kenya cash transfer programmes for orphans and vulnerable children ${ }^{1}$}

The aim of the Kenya CT-OVC is to protect orphans and other vulnerable children and encourage their human capital development. It is targeted to ultra-poor households (poorest 20 per cent) that contain an orphan or vulnerable child (OVC) - i.e. a child with at least one deceased parent, or living with a main caregiver who is chronically ill. The programme was initially implemented as pilot in 2004 and then gradually expanded since 2007; today the Kenya CT-OVC reaches over 160,000 households, 350,000 OVC and is the country's largest social protection programme. Participants receive US\$25 (KES 2,000) per month (paid every two months) which represents approximately 20 per cent of beneficiary consumption. Similarly to other programmes implemented in Sub-Saharan African countries, the Kenya CT-OVC is unconditional, although caregivers are informed about the aim of the programme and their responsibilities towards the care and protection of the resident OVCs.

The selection of participants is done in three stages ${ }^{2}$. First, a list of eligible households is prepared by an OVC Committee formed in each Location according to the demographic and poverty criteria. Second, the central office of the programme - located within the Ministry of Gender, Children and Social Development - assesses the eligibility criteria of the selected households and ranks them after administering an additional questionnaire with detailed socio-economic information. In the last stage, about 20 per cent of the poorest households that meet the eligibility are enrolled in each Location. When there are more eligible households than there is budget available, households are then ranked according to the age of the household head, resulting in a majority of elderly household heads receiving funds.

\section{Evaluation design, data and descriptive statistics}

\subsection{Evaluation design}

Prior to programme expansion of the CT-OVC in 2007, Oxford Policy Management (OPM) was contracted by UNICEF to implement an impact evaluation to track the impact of the programme on the core indicators of household consumption and food security, child health, and schooling. The design entailed a cluster randomised longitudinal design with a baseline household survey conducted in 2007 and a 24 month follow-up in 2009. The ethical rationale for the design was that the programme could not expand to all eligible Locations at the same time, so Locations where entry would occur later in the expansion cycle could be used as control sites to measure the impact. In the seven districts across the country that were scheduled to enter the programme in 2007 (Kisumu, Homa Bay, Migori, Suba, Nairobi, Garissa, and Kwale), four Locations were identified as eligible, two were randomised for immediate implementation, and the remaining two served as delayed entry control Locations. The targeting of households was carried out in all Locations and from the eligibility lists a sample of households was drawn, two-thirds from intervention Locations and the remaining third from control sites. Results from the impact evaluation have been reported by the Kenya CT-OVC Evaluation Team (2012a, b). In 2011 we returned to the households in the original evaluation sample that had been re-interviewed in 2009 and administered the same household survey along with a module covering preferences and expectations, administered

The text for this section is based on Handa et al (2014).

Some revisions have been introduced but the overall targeting process remain the same. 
to the main respondent. The 2011 study was approved by the University of North Carolina Institutional Review Board (UNC IRB) and the Kenya Medical Research Institute Ethics Review Committee.

\subsection{Attrition ${ }^{3}$}

The initial study period coincided with a time of political turmoil in Kenya resulting from the disputed national elections in December 2007. Over 1,000 people died and approximately 400,000 people were internally displaced at this time. Consequently, attrition between the baseline and the first follow-up in 2009 was 17 per cent and concentrated in Kisumu and Nairobi, the two Locations in the study that experienced the most election-related unrest. Attrition between the 2009 and 2011 rounds was only 5 per cent. Table 2.1 shows that the means of selected demographic and poverty measures for households in each arm were stable across the three waves despite the relatively high attrition rate between 2007 and 2009 , indicating that the representativeness of the sample remained intact.

A detailed analysis of attrition was conducted and reported in Handa et al (2014). That analysis shows that the probability of attriting was 19 and 9 percentage points higher for households in Nairobi and Kisumu respectively (the precise districts where election violence was most concentrated), and the determinants of attriting were the same across the two arms. The authors conclude, based on their analysis, that selective attrition is unlikely to be a concern in these data.

\subsection{Baseline balance}

The figures in bold in Table 2.1 indicate statistical significance between the intervention and the control arms of the study in each wave. The poverty-related variables are balanced across arms in each wave, but there are statistically significant differences in the age, sex and schooling levels of household heads across arms. This is due to the prioritisation process that occurred at the central Ministry because the number of households on the eligibility list typically exceeded the budget. This prioritisation process effectively gave the most weight to elderly-headed households. Since the final prioritisation process was not conducted in control Locations (as they were not scheduled to enter the programme immediately), households in the control arm of the study were drawn from a slightly larger eligibility list than those from the intervention arm, resulting in the differences in heads' characteristics observed in Table 2.1. It is important to note however that there is no element of self-selection into the programme; household eligibility was completely supply-driven and take-up was universal. 
Table 2.1 Household characteristics by wave and intervention status in the CT-OVC Evaluation Sample

\begin{tabular}{|c|c|c|c|c|c|c|c|}
\hline & \multirow{2}{*}{ Sample: } & \multicolumn{2}{|c|}{$\underline{2007}$} & \multicolumn{2}{|c|}{$\underline{2009}$} & \multicolumn{2}{|c|}{$\underline{2011}$} \\
\hline & & $\mathrm{T}$ & C & $\mathrm{T}$ & C & $\mathrm{T}$ & C \\
\hline \multicolumn{8}{|l|}{ Demographics } \\
\hline Household size & & 5.48 & 5.79 & 5.54 & 5.81 & 5.53 & 5.82 \\
\hline Residents $0-5$ years & & 0.66 & 0.86 & 0.68 & 0.85 & 0.67 & 0.86 \\
\hline Residents 6-11 years & & 1.21 & 1.33 & 1.23 & 1.32 & 1.23 & 1.31 \\
\hline Residents $12-17$ years & & 1.40 & 1.38 & 1.40 & 1.39 & 1.40 & 1.40 \\
\hline Residents $18-45$ years & & 1.12 & 1.45 & 1.13 & 1.46 & 1.13 & 1.46 \\
\hline Residents $46-64$ years & & 0.59 & 0.36 & 0.60 & 0.37 & 0.60 & 0.38 \\
\hline Residents $65+$ years & & 0.51 & 0.42 & 0.50 & 0.41 & 0.51 & 0.41 \\
\hline Female head & & 0.65 & 0.57 & 0.65 & 0.59 & 0.65 & 0.59 \\
\hline Age of head in years & & 62.34 & 56.06 & 62.21 & 56.20 & 62.55 & 56.55 \\
\hline Head not completed primary & & 0.53 & 0.38 & 0.53 & 0.38 & 0.53 & 0.38 \\
\hline \multicolumn{8}{|l|}{ Poverty } \\
\hline Per adult equiv. monthly exp. (KES) & & 1533.30 & 1501.25 & 1541.77 & 1459.94 & 1550.14 & 1441.99 \\
\hline Walls of mud/dung/grass/sticks & & 0.75 & 0.84 & 0.75 & 0.86 & 0.74 & 0.87 \\
\hline Roof of mud/dung/grass/sticks & & 0.23 & 0.22 & 0.23 & 0.23 & 0.22 & 0.22 \\
\hline Floor of mud/dung & & 0.66 & 0.74 & 0.65 & 0.77 & 0.66 & 0.79 \\
\hline No toilet & & 0.55 & 0.56 & 0.55 & 0.56 & 0.54 & 0.56 \\
\hline Unprotected water source & & 0.62 & 0.68 & 0.61 & 0.70 & 0.61 & 0.70 \\
\hline \multicolumn{8}{|l|}{ Region } \\
\hline Garissa & & 0.10 & 0.06 & 0.11 & 0.06 & 0.09 & 0.05 \\
\hline Homa Bay & & 0.12 & 0.13 & 0.12 & 0.13 & 0.12 & 0.14 \\
\hline Kisumu & & 0.18 & 0.23 & 0.18 & 0.22 & 0.18 & 0.22 \\
\hline Kwale & & 0.08 & 0.09 & 0.08 & 0.10 & 0.08 & 0.11 \\
\hline Migori & & 0.23 & 0.23 & 0.22 & 0.25 & 0.22 & 0.26 \\
\hline Nairobi & & 0.13 & 0.10 & 0.13 & 0.07 & 0.13 & 0.06 \\
\hline Suba & & 0.15 & 0.16 & 0.16 & 0.16 & 0.17 & 0.17 \\
\hline $\mathrm{N}$ & 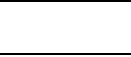 & 1540 & 754 & 1325 & 583 & 1266 & 545 \\
\hline
\end{tabular}

\subsection{Descriptive statistics}

Inter-temporal decision-making is measured in the survey through a hypothetical question as follows: "Suppose that you suddenly win money in the Lotto. If you could choose between these payment options which do you choose?" Respondents were presented with six payment options and for each option the immediate monetary payment was KES 1,500, while the future payoffs were KES 1,$250 ; 1,500 ; 3,000 ; 4,500 ; 7,000$; and 9,000. ${ }^{4}$ In Figure 2.2, we show the proportion of respondents that would wait for each value of future money. We also construct an ordinal variable classifying individuals by the value at which they would 'switch', that is, that they move from not waiting to waiting for future money. This ranges from 1 (most patient) to 7 (never switch); a value of 3 indicates for example that the individual switches at KES 3,000 (we refer to this variable as IES in the text below). As a further step, we build two dummy variables for 'patient' and 'impatient' participants that respectively

4 The survey instrument is available at www.cpc.unc.edu/projects/transfer/countries/kenya. The future amounts were not asked in this order-see instrument for exact ordering. 
identify people willing to wait for payments lower than KES 3,000 and those who never accept to wait for future money. As can be seen in Figure 2.1, about 16 per cent of participants are impatient (IES = 7) since they "always" prefer to take money today. On the other hand, about 26 per cent of people are patient since they are willing to delay gratification even for a smaller reward (about 18 per cent). Moreover, we observe a jump in the percentage of people willing to delay gratification by 56 point (from 22 to 78 per cent) from a future value of KES 1,500 to KES 3,000 (Figure 2.2). Lastly, Figure 2.2 confirms that the share of participants willing to delay monetary gratification rises as the value of future monetary rewards increases.

Figure 2.1 Individual switching points (IES) (1= patient; 7 = impatient)

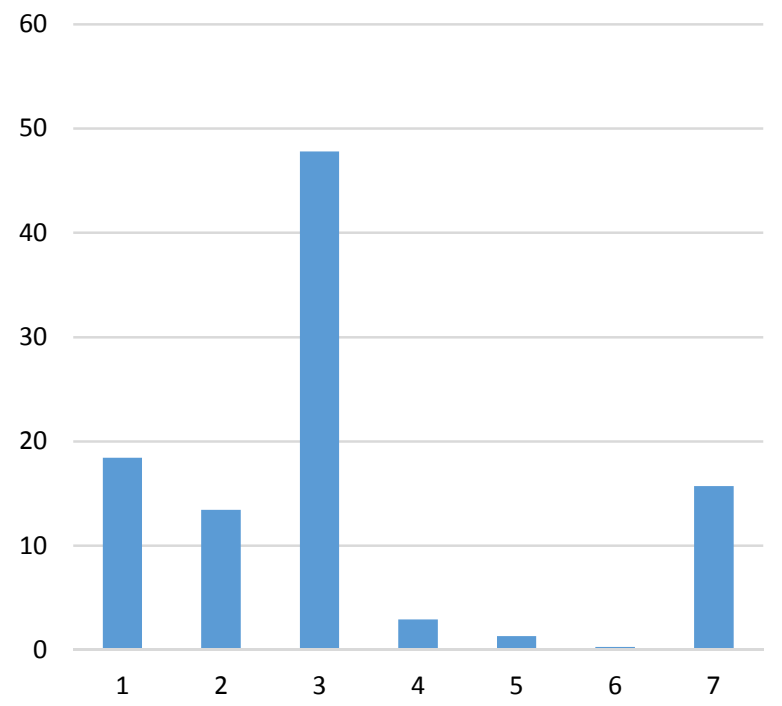

Figure 2.2 Per cent who will wait one month by future value

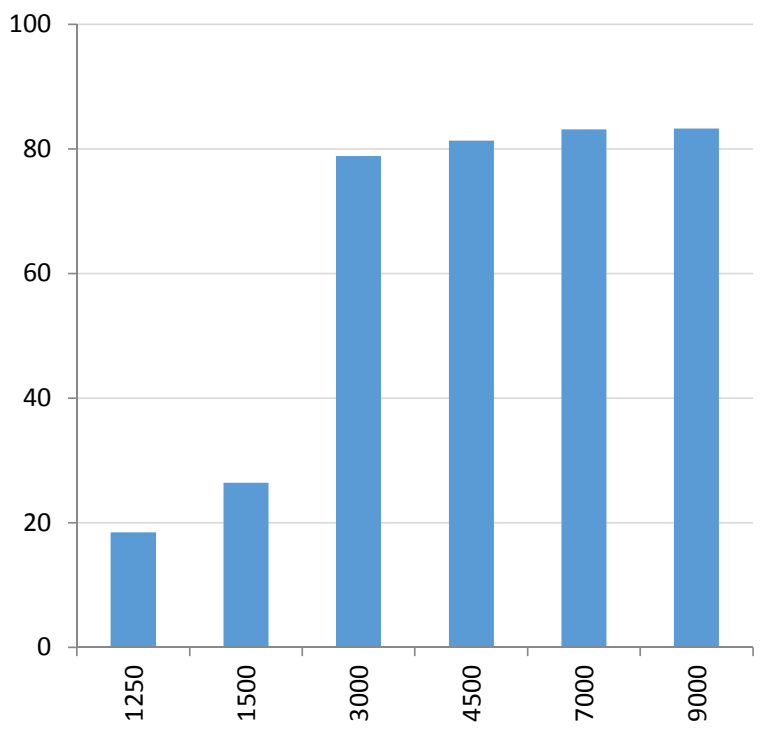

As reported above, theoretical and empirical evidence suggests that time discounting changes across age groups (Bishai 2004). In particular, inter-temporal choices 'manifest [itself] in extremely different degrees in different individuals, and even in the same individual at different times' (Bohm-Bawerk 1891, quoted in Becker and Mulligan 1997: 731 - 732). Figure 2.3 depicts the mean value of IES across the age distribution in our sample-the graph is U-shaped, declining from young to middle age and then rising toward old age. Young people are less patient than other groups reporting an IES index near 3.5 points though it is important to note that there are only 77 respondents under age 24 in the sample. Older adults (age 60 and above) report a mean IES index of 3.4 points while middle-aged adults are the most patient showing an IES index close to 3.1 . 


\section{Figure 2.3 Impatience by age}

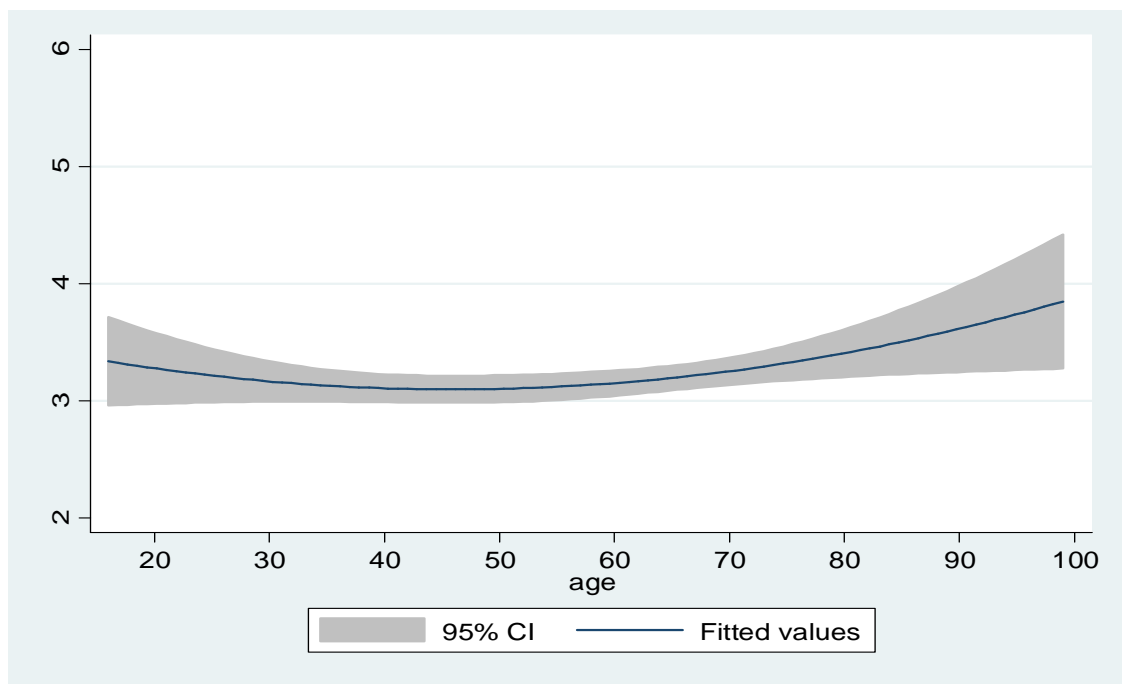

As reported in the literature, our data also shows gender differences (Figure 2.4). Although the IES index is U-shaped for both groups, changes across the ages seem less evident for females than for males. Moreover, females are less patient than males during young and adult life. However, Figure 2.4 shows that females become more patient than males during old age.

Figure 2.4 Impatience by age and sex

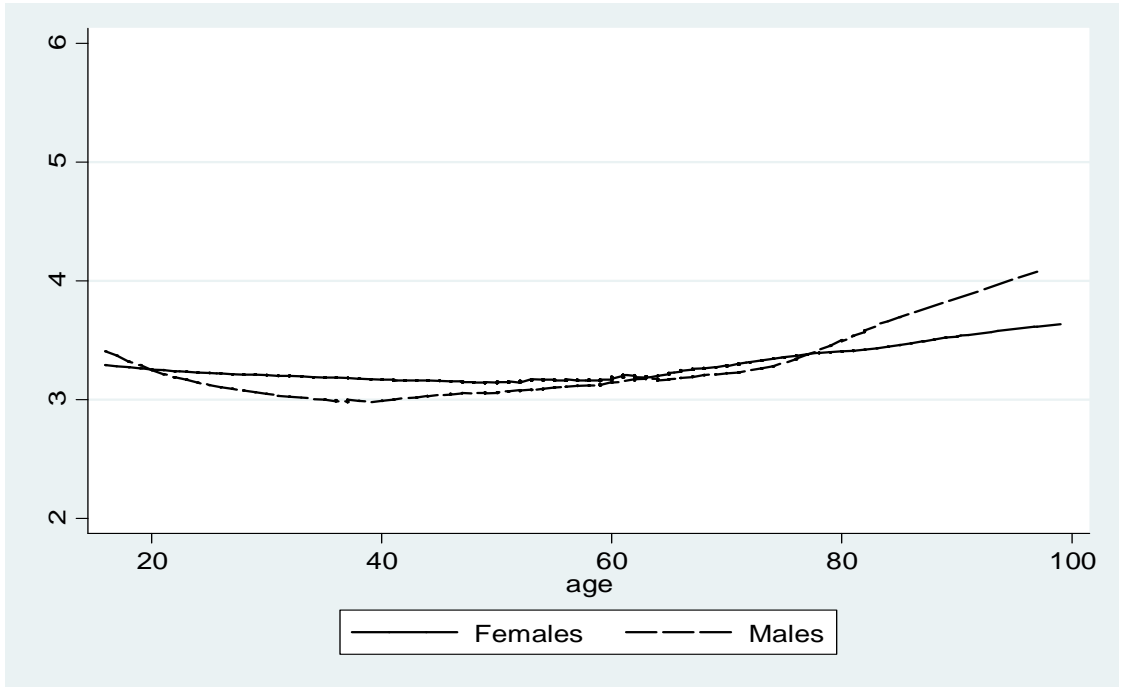

Comparing the treated and the control group, Table 2.2 shows that the mean differences are smaller than one percentage point for payments lower than KES 3,000, while they range between 3.4 and 4.4 points for the remaining payment choices. The mean difference between the two groups is smaller than one point for the IES index, but the control group is 3 percentage points more likely to never wait for money (last row of Table 2.2). 
Table 2.2 Mean differences in per cent willing to wait by study arm and amount

\begin{tabular}{lccc}
\hline & T & C & $\begin{array}{c}\text { p-value difference in } \\
\text { means }\end{array}$ \\
\hline Wait for 1250 & 19.1 & 19.5 & 0.84 \\
Wait for 1500 & 26.4 & 26.3 & 0.96 \\
Wait for 3000 & 78.4 & 75.0 & 0.13 \\
Wait for 4500 & 81.1 & 77.5 & 0.09 \\
Wait for 7000 & 83.1 & 78.7 & 0.03 \\
Wait for 9000 & 83.1 & 79.6 & 0.09 \\
IES & 3.2 & 3.3 & 0.14 \\
1 if wait for 1250 or 1500 & 31.8 & 32.3 & 0.85 \\
1 if never wait & 16.0 & 19.2 & 0.11 \\
\hline $\mathrm{N}$ & 1280 & 525 &
\end{tabular}

Figure 2.5 traces the mean value of IES by age group for the two study arms. While the overall difference in means is not statistically different (Table 2.2), Figure 2.5 suggests that there may be differences in programme effects by age group, particularly at middle and older ages.

Figure 2.5 Impatience by age (local polynomial fit)

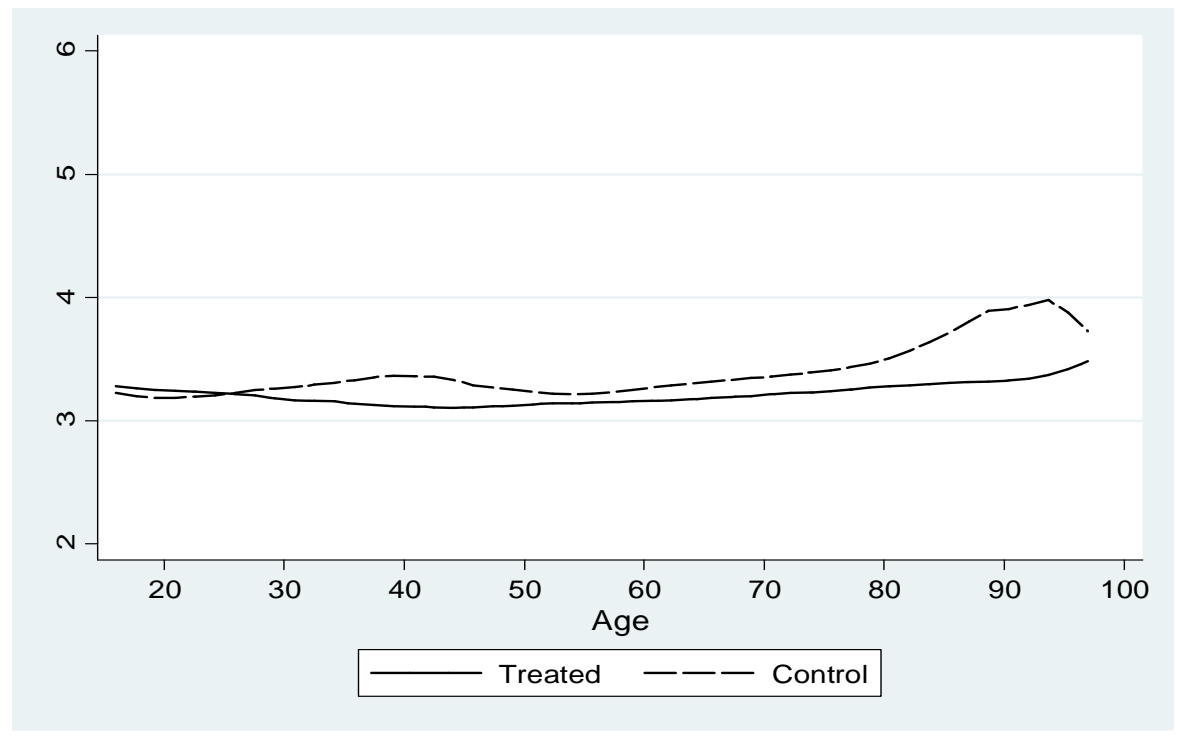

Figure 2.6 and 2.7 show local linear regression (lowess) estimates of the dummy variable for 'impatience' (never waiting for future money) by age and gender for each study arm. These figures confirm that people in the middle age group are more patient than others. However they also show that males in the treated group are always more patient than those in the control group, while for females the differences appear to interact with age, with large potential treatment effects between ages 30-50 and then later in life. 
Figure 2.6 Impatience by age: female (local polynomial fit)

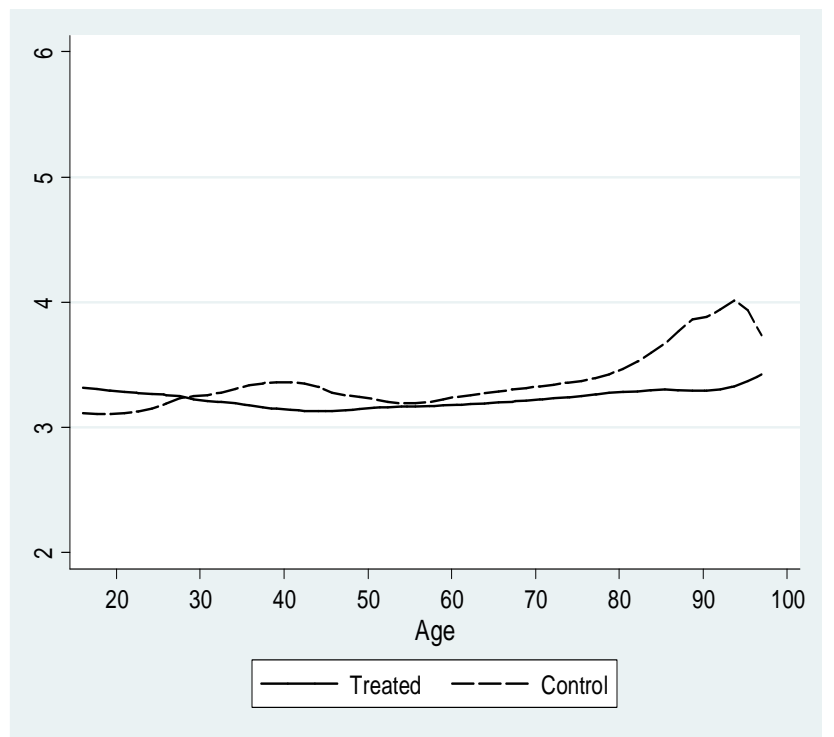

Figure 2.7 Impatience by age: male (local polynomial fit)

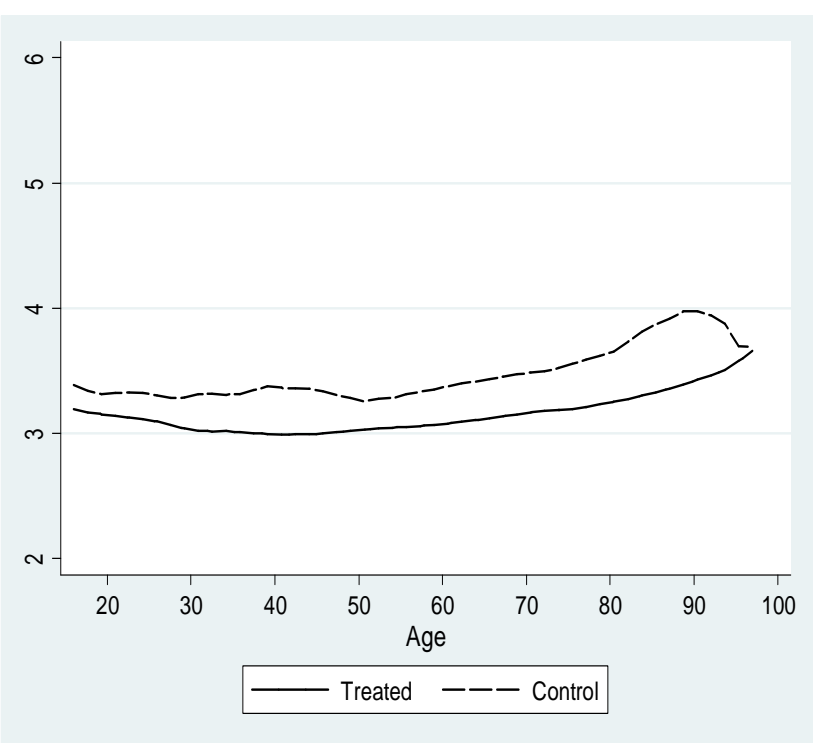

\section{The impact of the programme on time discounting}

\subsection{The empirical strategy}

To assess the impact of the programme on inter-temporal choice we estimate model 1 which expresses individual preferences $(y)$ as a function of different individual and household characteristics, respectively identified with $i$ and $h$ subscript variables. In the former group we include age, education, health status and sex while in the latter we include household size, demographic composition, per capita consumption expenditure, housing characteristics and the district of residence; all control variables are measured at baseline values. We capture the impact of the programme through a dummy variable $(T)$ that takes the value 1 if the respondent lives in a treatment household.

$y_{i}=\alpha+\beta_{1} T_{h}+\beta_{2} X_{i}+\beta_{3} X_{h}+\varepsilon_{i}$

As reported above, our hypothesis is that the programme has heterogeneous effects by ages and gender. Thus - in a first stage - we test the impact of the programme on three ages groups, i.e. young (aged less than 25 years old), adult (aged $25-59$ ) and older adult (aged more than 59). Then we separate our sample by gender and interact the age group dummies with the indicator for treatment status.

Recall that there were small differences in demographic characteristics of household heads between treatment and control arms due to the fact that the control households were sampled from the full eligibility list while treatment households were sampled from the prioritised list. We address this using inverse probability weights (IPW) derived from a regression that predicts the likelihood of treatment given a vector of household and individual characteristics. Given the importance of age in the prioritisation process this regression is close to saturated in age and results are shown in the Appendix, as is the distribution of the probability of being treated weighted by the IPW. Table 3.1 shows the mean characteristics of the control group after applying the IPW-these are now much more aligned to those of 
the treatment group. We continue to explicitly control for these covariates (measured at the baseline) in our regression estimates.

Table 3.1 Mean characteristics of respondents of behavioural module

\begin{tabular}{lcccc}
\hline & T & C (unweighted) & C (weighted) & p-value difference (1) vs. (3) \\
& $(1)$ & $(2)$ & $(3)$ & 0.03 \\
\hline Age in years & 57.3 & 49.2 & 59.1 & 0.57 \\
Female & 79.3 & 72.2 & 77.3 & 0.68 \\
Partner in household & 34.5 & 40.4 & 33.5 & 0.91 \\
Can read & 29.9 & 44.0 & 29.9 & 0.14 \\
Chronically ill (baseline) $^{1}$ & 14.9 & 14.1 & 17.8 & 0.98 \\
Disabled (baseline) $^{1}$ & 6.3 & 4.0 & 6.3 & \\
\hline $\mathrm{N}$ & 1280 & 525 & 525 & \\
\hline 1/ Self-reported. Estimates in column (3) weighted by inverse probability weight. &
\end{tabular}

\subsection{The impact of the programme on time discounting: full sample}

Table 3.2 reports the regression results from estimating model (1). None of the coefficients for the treatment effect are statistically significant indicating that receipt of the cash transfer does not affect time discounting in the full sample. However, there are some interesting results related to age, education, disability and the presence of a partner in the household. The age coefficients are negative and statistically significant for payments higher than KES 3,000 while illiterate and disabled people are less willing to wait for future payments than others.

Table 3.2 Determinants of time discounting with inverse probability weights

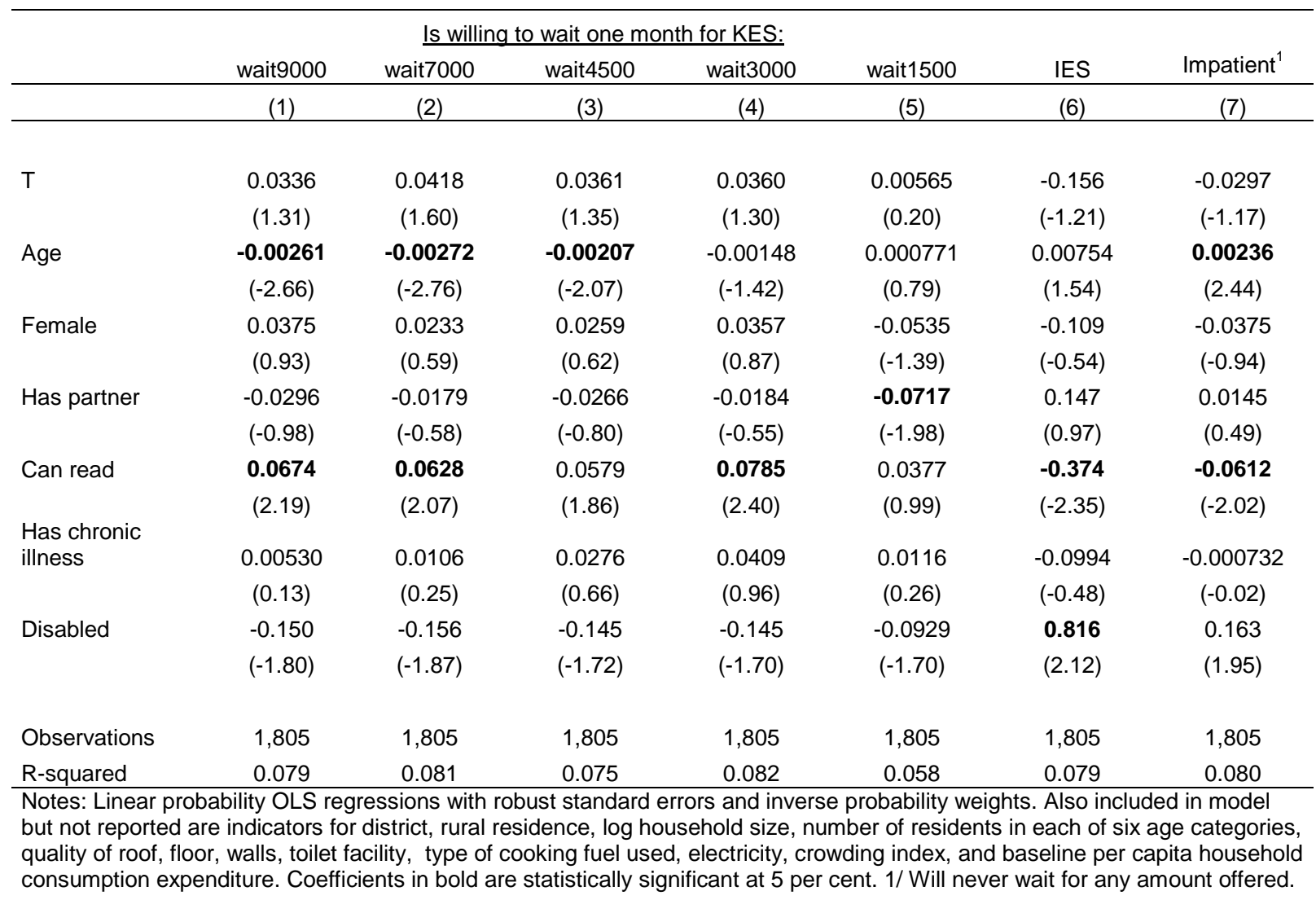




\subsection{The impact of the programme on time discounting across age groups}

Our main hypothesis is that the programme has heterogeneous effects by age and gender. Thus - in this section - we test the impact of the programme on time discounting by age groups. The results of the Ordinary Least Squares regression (OLS) regression estimates of treatment effects on young people aged less than 25 years old are shown in Table 3.3. Treatment status coefficients are large (16 percentage points) for higher payment values but not statistically significant, likely due to the small sample size in this age group. Although this small sample, coefficients for education are statistically significant at high future valuesliterate respondents are more likely to wait for future money.

Table 3.3 Determinants of time discounting with inverse probability weights: people aged less than 25 years old

\begin{tabular}{|c|c|c|c|c|c|c|c|}
\hline & & Is willin & wait one mc & for KES: & & & \\
\hline & wait9000 & wait7000 & wait4500 & wait3000 & wait1500 & IES & Impatient ${ }^{1}$ \\
\hline & (1) & (2) & (3) & (4) & (5) & (6) & (7) \\
\hline $\mathrm{T}$ & -0.160 & -0.160 & -0.0429 & -0.203 & 0.0409 & 0.710 & 0.160 \\
\hline & $(-1.52)$ & $(-1.52)$ & $(-0.34)$ & $(-1.65)$ & $(0.37)$ & $(1.36)$ & (1.52) \\
\hline Age & -0.0124 & -0.0124 & -0.0115 & -0.0238 & 0.00886 & 0.0420 & 0.0124 \\
\hline & $(-0.65)$ & $(-0.65)$ & $(-0.44)$ & $(-1.05)$ & $(0.30)$ & $(0.42)$ & $(0.65)$ \\
\hline Female & 0.0273 & 0.0273 & 0.0261 & 0.0977 & 0.0976 & -0.405 & -0.0273 \\
\hline & $(0.22)$ & $(0.22)$ & $(0.21)$ & $(0.82)$ & $(0.83)$ & $(-0.73)$ & $(-0.22)$ \\
\hline Has partner & -0.128 & -0.128 & -0.137 & -0.124 & -0.223 & 0.886 & 0.128 \\
\hline & $(-1.09)$ & $(-1.09)$ & $(-1.09)$ & $(-0.99)$ & $(-1.86)$ & (1.58) & (1.09) \\
\hline Can read & 0.248 & 0.248 & -0.0239 & 0.185 & -0.238 & -0.550 & -0.248 \\
\hline & $(2.45)$ & $(2.45)$ & $(-0.18)$ & $(1.84)$ & $(-1.50)$ & $(-1.05)$ & $(-2.45)$ \\
\hline $\begin{array}{l}\text { Has chronic } \\
\text { illness }\end{array}$ & 0.214 & 0.214 & 0.371 & 0.0569 & 0.233 & -2.003 & -0.214 \\
\hline & $(1.20)$ & $(1.20)$ & $(1.60)$ & $(0.28)$ & (1.49) & $(-2.16)$ & $(-1.20)$ \\
\hline Disabled & 0.298 & 0.298 & 0.0650 & 0.325 & 0.184 & -0.552 & -0.298 \\
\hline & (1.01) & (1.01) & $(0.13)$ & $(1.06)$ & $(0.78)$ & $(-0.35)$ & $(-1.01)$ \\
\hline Observations & 76 & 76 & 76 & 76 & 76 & 76 & 76 \\
\hline R-squared & 0.478 & 0.478 & 0.488 & 0.520 & 0.367 & 0.475 & 0.478 \\
\hline
\end{tabular}

Table 3.4 shows the impact of the programme on time discounting for people aged $26-59$ years old. In contrast to the previous case, people in the treated group are more willing to wait for future values higher than KES 1,500. In particular, treatment status coefficients are positive - ranging around 7 and 8 points - and statistically significant at the highest future values. Similarly, the treatment effect is negative and significant for the impatience dummy and the impatience index (where higher values indicate impatience). Looking to the other variables, literacy again increases the likelihood of delaying payment while disability and sex of respondent are not related to discounting in this age group. 
Table 3.4 Determinants of time discounting with inverse probability weights: people aged 25-59 years old

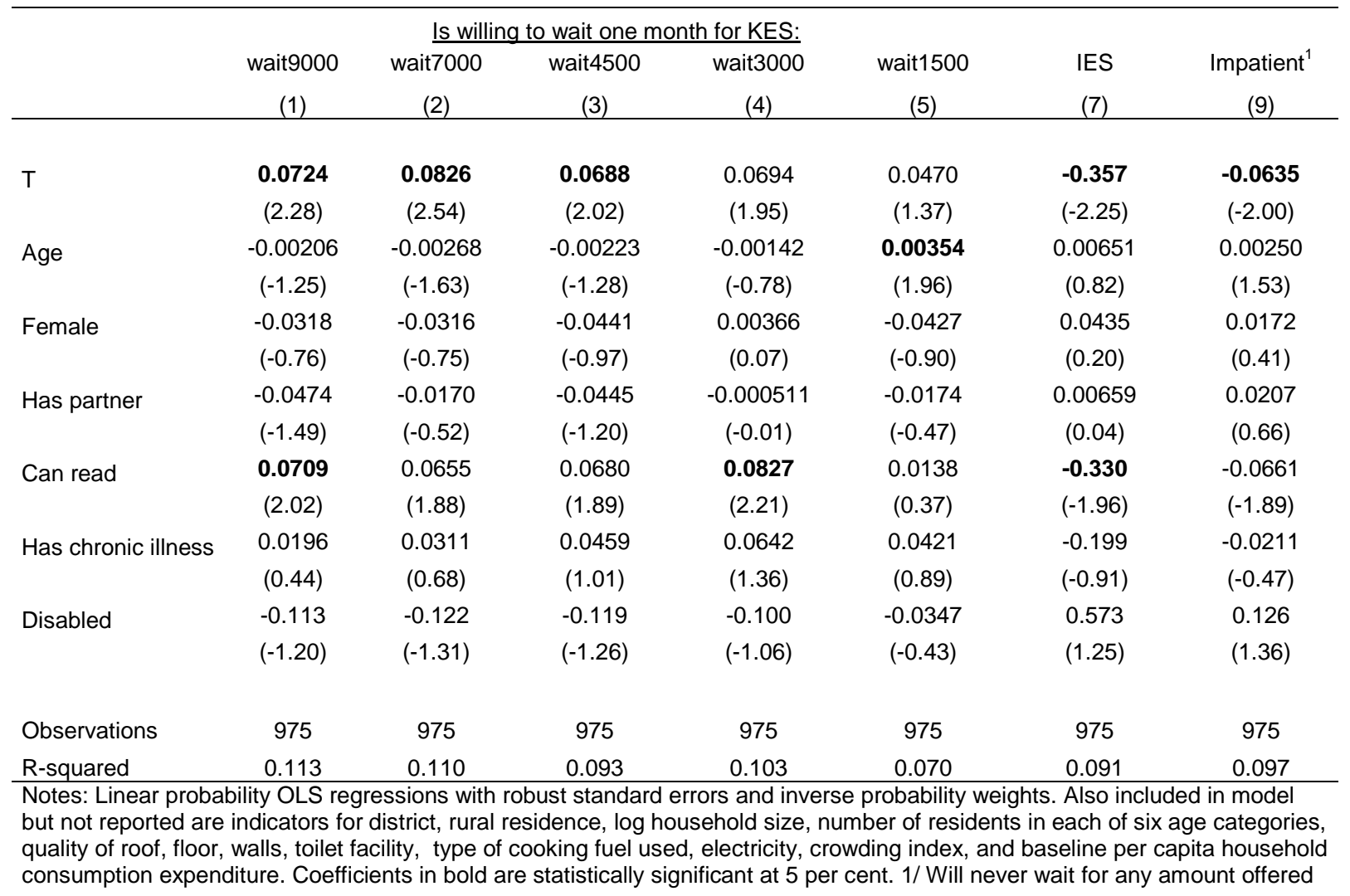

Finally, Table 3.5 reports the impact of the programme on time discounting for people older than 59 years old. None of the treatment effects are statistically significant in this sub-sample thus the cash payments have no effects on time discounting for elderly people. Interestingly in this sample neither literacy nor disability status have an impact on time discounting. 
Table 3.5 Determinants of time discounting with inverse probability weights: people aged more than 59 years old

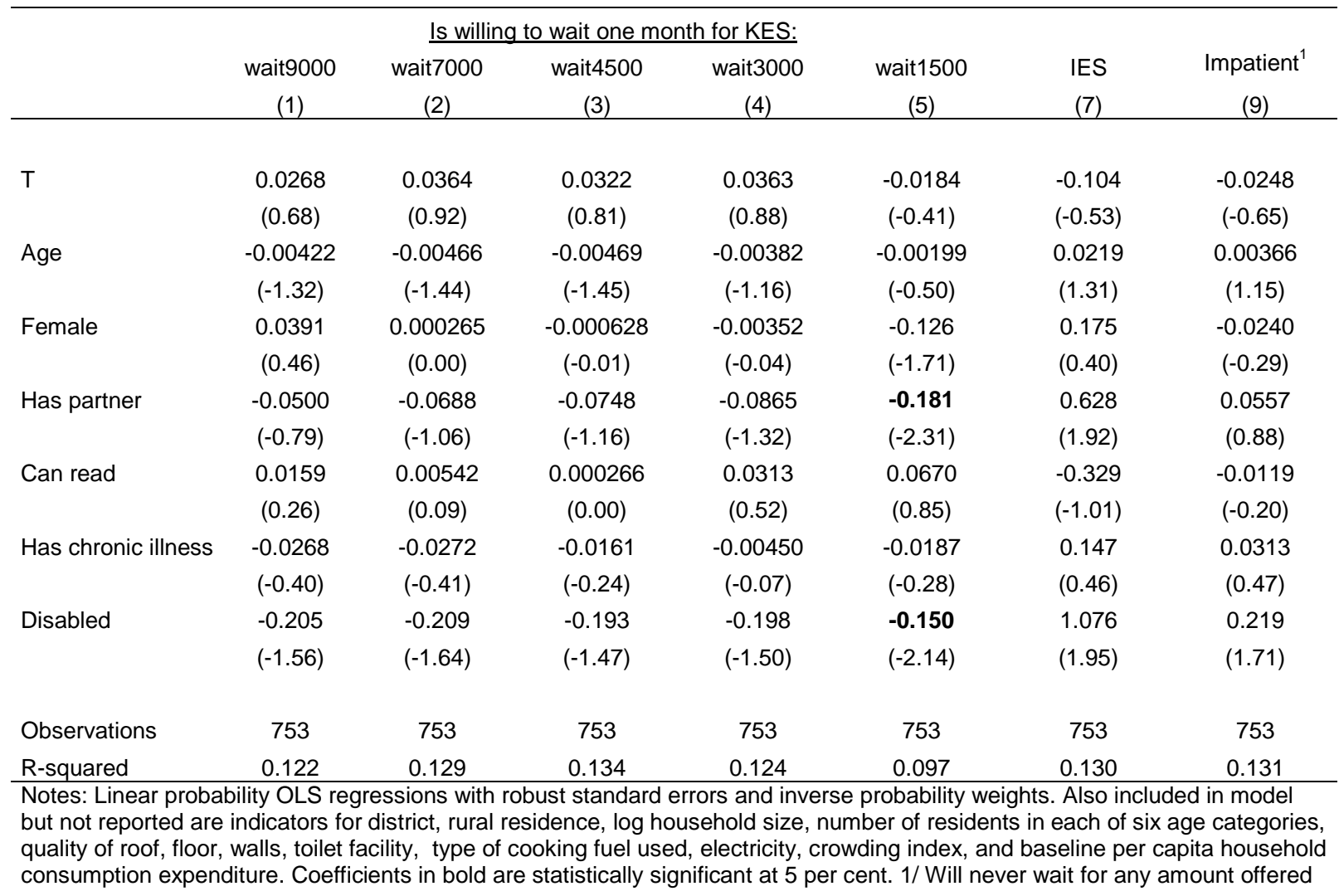

\subsection{The impact of the programme on time discounting by ages and gender}

Given the lowess graphs presented earlier it appears as if there may be different treatment effects by age and gender and so in Tables 3.6 and 3.7 we display results by gender and interact the treatment dummy with age group to test for heterogeneous treatment effects by age-gender. In this framework, the treatment dummy measures the treatment effect among the youngest age group (the excluded or reference group). Within the treatment group, age differences in treatment effects are given by the sum of the respective age dummy and interaction term. Within each age group, differences across study arms are given by the sum of the treatment dummy and the respective age-interaction term.

For males (Table 3.6), neither treatment nor age dummy coefficients nor their interactions are statistically significant. This suggests that for men, the treatment effect is stable across the age-profile. However, there is a larger strong effect of literacy among men, with those who can read about 12 points more likely to wait for future money relative to those who cannot. 
Table 3.6 Determinants of time discounting with inverse probability weights: males

\begin{tabular}{|c|c|c|c|c|c|c|c|}
\hline & & Is wil & wait one & for KES: & & & \\
\hline & $\begin{array}{c}\text { wait9000 } \\
\text { (1) }\end{array}$ & $\begin{array}{c}\text { wait7000 } \\
(2) \\
\end{array}$ & $\begin{array}{c}\text { wait4500 } \\
(3)\end{array}$ & $\begin{array}{c}\text { wait3000 } \\
(4)\end{array}$ & $\begin{array}{c}\text { wait1500 } \\
\text { (5) }\end{array}$ & $\begin{array}{l}\text { IES } \\
(7)\end{array}$ & $\begin{array}{c}\text { Impatient }^{1} \\
(9)\end{array}$ \\
\hline $\mathrm{T}$ & 0.0599 & 0.0501 & 0.223 & 0.0282 & -0.186 & -0.0174 & -0.0492 \\
\hline & $(0.43)$ & $(0.35)$ & $(1.31)$ & $(0.17)$ & $(-1.05)$ & $(-0.03)$ & $(-0.34)$ \\
\hline Age 25-59 years & -0.118 & -0.117 & 0.0820 & -0.125 & -0.0875 & 0.436 & 0.111 \\
\hline & $(-0.91)$ & $(-0.88)$ & $(0.51)$ & $(-0.86)$ & $(-0.52)$ & $(0.71)$ & $(0.83)$ \\
\hline$T^{*}$ Age $25-59$ years & 0.0675 & 0.0666 & -0.110 & 0.0788 & 0.226 & -0.554 & -0.0636 \\
\hline & $(0.44)$ & $(0.42)$ & $(-0.60)$ & $(0.44)$ & $(1.21)$ & $(-0.77)$ & $(-0.40)$ \\
\hline Age $60+$ years & -0.137 & -0.111 & 0.0819 & -0.0606 & 0.0848 & -0.147 & 0.104 \\
\hline & $(-0.89)$ & $(-0.71)$ & $(0.45)$ & $(-0.37)$ & $(0.40)$ & $(-0.18)$ & $(0.67)$ \\
\hline$T^{\star}$ Age $60+$ years & 0.0409 & 0.00796 & -0.180 & -0.00767 & 0.0132 & 0.218 & -0.0127 \\
\hline & $(0.25)$ & $(0.05)$ & $(-0.94)$ & $(-0.04)$ & $(0.06)$ & $(0.27)$ & $(-0.08)$ \\
\hline Has partner & 0.102 & 0.125 & 0.146 & 0.172 & -0.00963 & -0.597 & -0.129 \\
\hline & $(1.59)$ & $(1.98)$ & $(2.30)$ & $(2.72)$ & $(-0.14)$ & $(-1.81)$ & $(-2.05)$ \\
\hline Can read & 0.137 & 0.122 & 0.115 & 0.122 & 0.104 & -0.684 & -0.128 \\
\hline & (2.59) & $(2.38)$ & $(2.10)$ & (2.29) & $(1.57)$ & $(-2.44)$ & $(-2.52)$ \\
\hline Has chronic illness & -0.0621 & -0.0667 & -0.0497 & -0.00251 & 0.0619 & 0.196 & 0.0716 \\
\hline & $(-0.84)$ & $(-0.91)$ & $(-0.68)$ & $(-0.03)$ & $(0.80)$ & $(0.50)$ & $(0.98)$ \\
\hline Disabled & -0.0942 & -0.124 & -0.117 & -0.0959 & -0.113 & 0.782 & 0.129 \\
\hline & $(-0.84)$ & $(-1.10)$ & $(-1.00)$ & $(-0.84)$ & $(-1.31)$ & $(1.58)$ & $(1.15)$ \\
\hline Observations & 421 & 421 & 421 & 421 & 421 & 421 & 421 \\
\hline R-squared & 0.239 & 0.237 & 0.223 & 0.227 & 0.113 & 0.220 & 0.248 \\
\hline
\end{tabular}

For women on the other hand, there appear to be strong heterogeneous treatment effects by age (Table 3.7) with all age and age-interaction terms statistically significant for outcomes other than KES 1,500. The sign patterns and magnitudes suggest that prime-age and older adults in the treatment group are the most patient. For example, prime-age women in the treatment group are 12.2 percentage points more likely to wait for KES 9,000 relative to young women $(-0.198+0.320)$ and older women are 0.038 percentage points more likely to wait for the same amount $(-0.213+0.251)$. Table 3.8 calculates the mean difference in the likelihood of waiting for different values based on the coefficients in Table 3.7 for ease of reference. The largest mean differences are found between middle and younger age women in the treatment group, with mean differences ranging from 12 to 22 percentage points (for KES 4,500). And the treatment effect is also largest among middle age women, ranging from 6-7 percentage points (column 3 of Table 3.8). The age effects within the treatment arm tend to be larger than the treatment effects within each age group. For example, in the prime age group, women in the treatment group are only 7 points more likely to wait for KES 7,000 relative to women in this age group in the control arm (column 3 of Table 3.8); however, within the treatment group middle-age women are 12 points more likely to wait for $\operatorname{KES~} 7,000$ compared to younger women. Overall these results confirm that treatment effect of the CTOVC appears to be largest among middle-age women, and among women in general. In particular, middle-age women are more patient followed by older and then younger women. 
Table 3.7 Determinants of time discounting with inverse probability weights, females

\begin{tabular}{|c|c|c|c|c|c|c|c|}
\hline & & Is willin & wait one $\mathrm{m}$ & for KES: & & & \\
\hline & wait9000 & wait7000 & wait4500 & wait3000 & wait1500 & IES & Impatient $^{1}$ \\
\hline & (1) & (2) & (3) & (4) & (5) & (7) & (9) \\
\hline $\mathrm{T}$ & -0.260 & -0.265 & -0.387 & -0.309 & 0.0557 & 1.754 & 0.247 \\
\hline & $(-3.14)$ & $(-3.18)$ & $(-4.21)$ & $(-3.47)$ & $(0.63)$ & $(2.86)$ & (3.01) \\
\hline Age $25-59$ years & -0.198 & -0.218 & -0.226 & -0.246 & 0.0944 & 1.302 & 0.171 \\
\hline & $(-3.90)$ & $(-4.03)$ & $(-4.23)$ & $(-4.39)$ & (1.41) & $(2.44)$ & $(3.46)$ \\
\hline $\mathrm{T}^{\star}$ Age $25-59$ years & 0.320 & 0.336 & 0.447 & 0.368 & -0.0208 & -2.030 & -0.300 \\
\hline & (3.48) & (3.59) & $(4.43)$ & (3.73) & $(-0.22)$ & $(-3.15)$ & $(-3.28)$ \\
\hline Age $60+$ years & -0.213 & -0.231 & -0.245 & -0.250 & 0.0902 & 1.401 & 0.189 \\
\hline & $(-3.57)$ & $(-3.81)$ & $(-3.98)$ & $(-3.82)$ & (1.17) & $(2.48)$ & (3.25) \\
\hline$T^{*}$ Age $60+$ years & 0.251 & 0.274 & 0.395 & 0.319 & -0.0577 & -1.840 & -0.246 \\
\hline & (2.63) & $(2.84)$ & (3.79) & (3.12) & $(-0.59)$ & $(-2.80)$ & $(-2.60)$ \\
\hline Has partner & -0.0521 & -0.0418 & -0.0609 & -0.0577 & -0.0975 & 0.348 & 0.0395 \\
\hline & $(-1.52)$ & $(-1.16)$ & $(-1.63)$ & $(-1.50)$ & $(-2.34)$ & $(2.00)$ & (1.17) \\
\hline Can read & 0.0599 & 0.0603 & 0.0553 & 0.0745 & 0.00139 & -0.308 & -0.0516 \\
\hline & $(1.60)$ & $(1.62)$ & $(1.47)$ & $(1.90)$ & $(0.03)$ & $(-1.59)$ & $(-1.39)$ \\
\hline Has chronic illness & 0.0302 & 0.0396 & 0.0507 & 0.0589 & 0.00234 & -0.220 & -0.0317 \\
\hline & $(0.78)$ & $(1.01)$ & $(1.30)$ & (1.43) & $(0.05)$ & $(-1.14)$ & $(-0.82)$ \\
\hline Disabled & -0.210 & -0.210 & -0.199 & -0.210 & -0.0805 & 0.981 & 0.217 \\
\hline & $(-1.84)$ & $(-1.82)$ & $(-1.74)$ & $(-1.78)$ & $(-1.11)$ & $(1.86)$ & (1.90) \\
\hline Observations & 1,383 & 1,383 & 1,383 & 1,383 & 1,383 & 1,383 & 1,383 \\
\hline R-squared & 0.075 & 0.072 & 0.074 & 0.077 & 0.067 & 0.078 & 0.074 \\
\hline
\end{tabular}

Notes: Linear probability OLS regressions with robust standard errors and inverse probability weights. Also included in model but not reported are indicators for district, rural residence, log household size, number of residents in each of six age categories, quality of roof, floor, walls, toilet facility, type of cooking fuel used, electricity, crowding index, and baseline per capita household consumption expenditure. Coefficients in bold are statistically significant at 5 per cent. 1/ Will never wait for any amount offered

Table 3.8 Mean differences in effects derived from coefficients in Table 3.7 (percentage points)

\begin{tabular}{lcccc}
\hline & \multicolumn{2}{c}{ Within treatment group } \\
& $\begin{array}{c}\text { Difference between }(<25) \\
\text { and (25-59) } \\
(1)\end{array}$ & $\begin{array}{c}\text { Difference between }(<25) \\
\text { and (60+) } \\
(2)\end{array}$ & $\begin{array}{c}\text { Difference between T vs C } \\
\text { Age group 25-59 }\end{array}$ & $\begin{array}{c}\text { Age group 60+ } \\
(3)\end{array}$ \\
\hline Delay amount (KES) & 0.12 & 0.07 & 0.06 & 0.01 \\
3000 & 0.22 & 0.15 & 0.06 & 0.01 \\
4500 & 0.12 & 0.04 & 0.07 & 0.01 \\
7000 & 0.12 & 0.04 & 0.06 & -0.01 \\
9000 & & & & \\
\hline
\end{tabular}




\section{Conclusions}

This paper investigates the role of age, gender and income shocks on time discounting using evaluation data from the Government of Kenya's largest social protection programme, the Kenya Cash Transfer for Orphans and Vulnerable Children (CT-OVC).

First, the analysis confirms that young people are less patient than other age groups. This is consistent with the theoretical literature that suggests that younger people are more impulsive and have greater difficulty making plans or foreseeing the consequences of their actions in the future. They become more patient as they get older and their cognitive control dominates their emotions. Yet, people become more impatient in old age because of the growing uncertainty about their life and the increasing pressure to obtain satisfaction as soon as possible. Second, this paper shows important gender differences in time discounting. In contrast to previous empirical evidence, females in our study population are less patient than males during young and middle-ages but become more patient relative men at older age. Third, we show that a national poverty targeted cash transfer affects time discounting among women but not men, an important result given that about two-thirds of beneficiary household heads are women in this programme. Moreover, treatment effects are highest among women age 25-59, followed by those age 60 and above.

These results are exciting in that they derive from a national cash transfer programme that is currently being taken to scale by the government of Kenya. The parameters of the Kenyan programme are similar to other national programmes in Eastern and Southern Africa suggesting an important degree of external validity. The results depict that policies for equity may also provide important efficiency benefits as well. In our specific setting, the Kenya CTOVC helps protect the most vulnerable groups in the short term by improving food security and consumption (Kenya CT-OVC Study Team 2012a); at the same time, the programme appears to promote forward looking decision-making with potentially important consequences in terms of investment in human capital and other investment. 


\section{Annex 1}

Annex 1 Probit estimates of probability of being in treatment group

\begin{tabular}{|c|c|c|}
\hline & Marginal Effect & Std. Error \\
\hline Female & 0.0413 & 0.0312 \\
\hline Partner in household & -0.0262 & 0.0283 \\
\hline Able to read & -0.0246 & 0.0277 \\
\hline Chronic illness & -0.00150 & 0.0325 \\
\hline Disabled & 0.0729 & 0.0418 \\
\hline Rural area & 0.242 & 0.0594 \\
\hline Per capita consumption ( $\mathrm{x} 10000)$ & -0.0111 & 0.027 \\
\hline Residents age $0-5$ & -0.00576 & 0.0305 \\
\hline Residents age 6-11 & 0.00601 & 0.0298 \\
\hline Residents age $12-17$ & 0.00637 & 0.0290 \\
\hline Residents age $18-45$ & -0.0817 & 0.0503 \\
\hline Residents age $46-64$ & 0.121 & 0.0686 \\
\hline Residents age $65+$ & 0.0214 & 0.0376 \\
\hline Log household size & -0.00398 & 0.128 \\
\hline Crowding & -0.0113 & 0.00842 \\
\hline Walls of mud/dung/grass/sticks & -0.120 & 0.0387 \\
\hline Roof of mud/dung/grass/sticks & 0.0188 & 0.0394 \\
\hline Floor of mud & -0.0479 & 0.0362 \\
\hline Cooking fuel biomass & 0.250 & 0.0586 \\
\hline Electricity & -0.0730 & 0.0778 \\
\hline No toilet & -0.00278 & 0.0264 \\
\hline Nairobi & 0.234 & 0.0503 \\
\hline Homa Bay & -0.333 & 0.0868 \\
\hline Migori & -0.335 & 0.0843 \\
\hline Kisumu & -0.360 & 0.0856 \\
\hline Suba & -0.269 & 0.0876 \\
\hline Kwale & -0.201 & 0.0891 \\
\hline Age $<30$ & -0.128 & 0.0651 \\
\hline Age $31-40$ & -0.345 & 0.0651 \\
\hline Age $41-45$ & -0.359 & 0.0730 \\
\hline Age $46-50$ & -0.190 & 0.0675 \\
\hline Age 51-55 & -0.151 & 0.0626 \\
\hline Age $56-60$ & -0.105 & 0.0581 \\
\hline Age 61-65 & -0.0284 & 0.0564 \\
\hline Age $66-75$ & 0.0132 & 0.0469 \\
\hline Residents age $18-45^{\star}$ residents $46-64$ & 0.0238 & 0.0198 \\
\hline Household size*residents $18-45$ & 0.00597 & 0.00342 \\
\hline Household size*residents 46-64 & -0.00710 & 0.00946 \\
\hline Log likelihood & \multicolumn{2}{|c|}{-916.14} \\
\hline Chi square (38) & \multicolumn{2}{|c|}{292.2} \\
\hline Psuedo R-square & \multicolumn{2}{|c|}{0.16} \\
\hline Observations & \multicolumn{2}{|c|}{1,805} \\
\hline
\end{tabular}

Estimates are used to derive probability scores for inverse probability weight calculation. See text for explanation. 


\section{Annex 2}

\section{Annex 2 Distribution of probability scores}
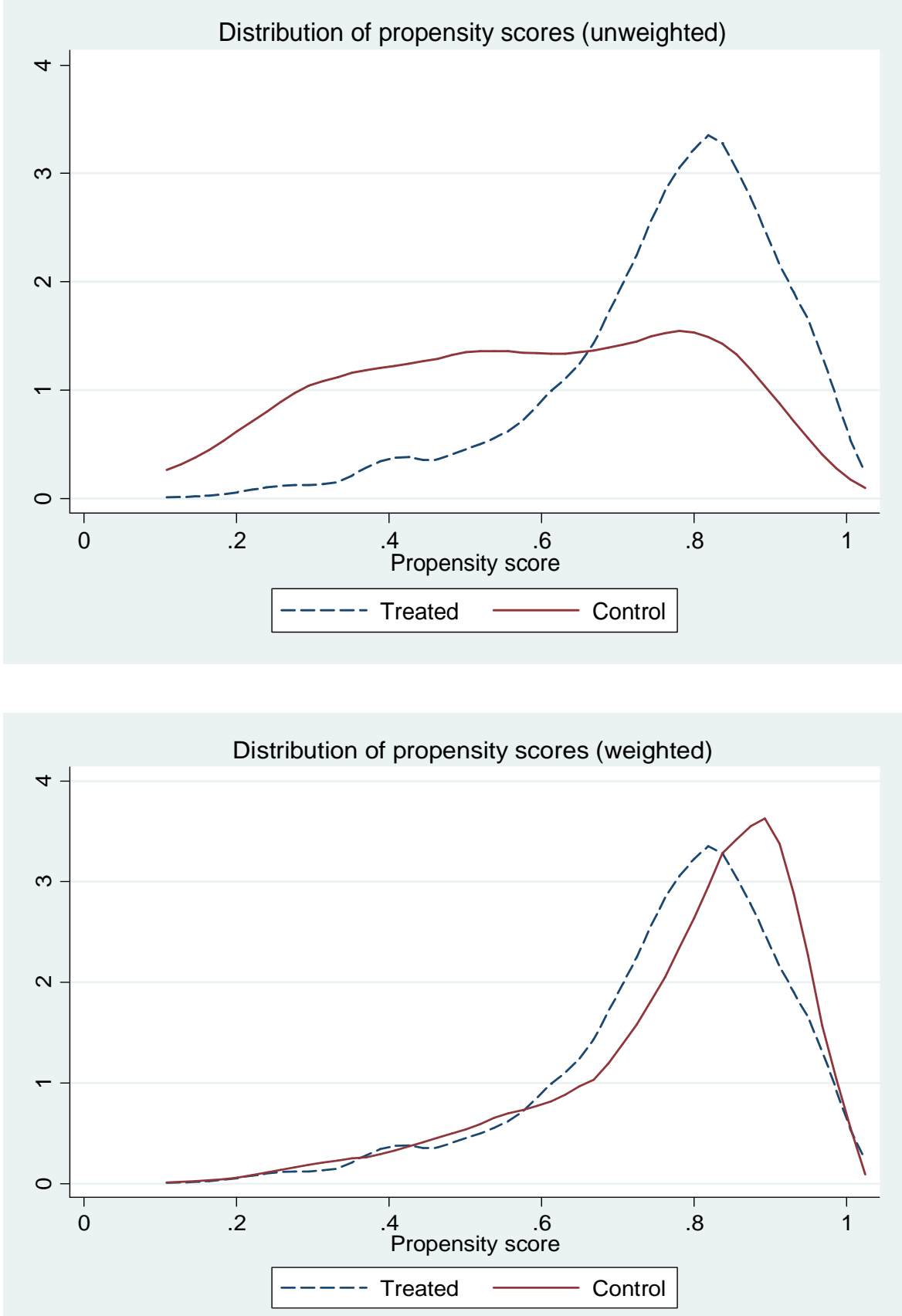


\section{References}

Akerlund, D.; Golsteyn, B.; Gronqvist, H. and Lindahl, L. (2014) 'Time Preferences and Criminal Behavior', IZA Discussion Paper 8168

Almås, I.; Cappelen, A.W.; Salvanes, K.G.; Sørensen, E.Ø. and Tungodden, B. (2012), 'Willingness to Compete: Family Matters', NHH Discussion Papers SAM 23/2012

Ashraf, N. (2009) 'Spousal Control and Intra-household Decision Making: An Experimental Study in the Philippines', American Economic Review 99.4: 1245-77

Ashraf, N.; Karlan, D. and Yin, W. (2006) 'Tying Odysseus to the Mast: Evidence from a Commitment Savings Product in the Philippines', Quarterly Journal of Economics 121.2: $635-72$

Bauer, M. and Chytilová, J. (2013) 'Women, Children and Patience: Experimental Evidence from Indian Villages', Review of Development Economics 17.4: 662-75

Becker, G.S. and Mulligan, C.B. (1997) 'The Endogenous Determination of Time Preference', Quarterly Journal of Economics: 729-58

Bishai, D.M. (2004) 'Does Time Preference Change with Age?', Journal of Population Economics 17.4: 583-602

Bradford, W.D.; Dolan, P. and Galizzi, M.M. (2014) Looking Ahead: Subjective Time Perception and Individual Time Discounting, Centre for Economic Performance, LSE (No. dp1255)

Burks, S.V.; Carpenter, J.P.; Goette, L. and Rustichini, A. (2009) 'Cognitive Skills Affect Economic Preferences, Strategic Behavior, and Job Attachment', Proceedings of the National Academy of Sciences 106.19: 7745-50

Carvalho, L.; Prina, S. and Sydnor, J. (2014) The Effect of Saving on Risk Attitudes and Intertemporal Choices, working paper

Chang, J.B.; Lusk, J.L. and Norwood, F.B. (2009) 'How Closely do Hypothetical Surveys and Laboratory Experiments Predict Field Behavior?', American Journal of Agricultural Economics 91.2: 518-34

Chu, C.Y.: Chien, H.K. and Lee, R.D. (2008) The Evolutionary Theory of Time Preferences and Intergenerational Transfers, National Bureau of Economic Research (No. w14185)

Dittrich, M. and Leipold, K. (2014) 'Gender Differences in Time Preferences', Economics Letters 122.3: 413-15

Green, L.; Myerson, J. and Ostaszewski, P. (1999) 'Discounting of Delayed Rewards Across the Life Span: Age Differences in Individual Discounting Functions,' Behavioural Processes 46.1: 89-96

Greene, A. (1986) 'Future Time Perspective in Adolescence: The Present of Things Future Revisited', Journal of Youth and Adolescence 15: 99-113 
Grisso, T.; Steinberg, L.; Woolard, J.; Cauffman, E.; Scott, E.; Graham, S.; et al. (2003) ' 'Juveniles' Competence to Stand Trial: A Comparison of Adolescents' and Adults' Capacities as Trial Defendants', Law and Human Behavior 27: 333-63

Handa, S.; Seidenfeld, D. and Tembo, G. (2013) The Impact of a Large Scale Poverty Targeted Cash Transfer Program on Inter-temporal Choice, Carolina Population Center, University of North Carolina at Chapel Hill

Handa, S.; Martorano, B.; Halpern, C.; Pettifor, A. and Thirumurthy, H. (2014) Subjective Well-being, Risk Perceptions and Time Discounting: Evidence from a Large-Scale Cash Transfer Programme, Innocenti Working Paper 2014-02, UNICEF Office of Research, Florence

Kenya CT-OVC Evaluation Team (Palermo et al.) (2012a) 'Impact of the Kenya CT-OVC on Household Spending', Journal of Development Effectiveness 4.1: 9-37

Kenya CT-OVC Evaluation Team (Handa et al.) (2012b) 'The Impact of the Kenya CT-OVC Program on Human Capital', Journal of Development Effectiveness 4.1: 38-49

Khwaja, A.; Silverman, D. and Sloan, F. (2007) 'Time Preference, Time Discounting, and Smoking Decisions', Journal of Health Economics 26.5: 927-49

Liu, W. and Aaker, J. (2007) 'Do you Look to the Future or Focus on Today? The Impact of Life Experience on Intertemporal Decisions', Organizational Behavior and Human Decision Processes 102.2: 212-25

Löckenhoff, C.E.; Laucks, S.S.; Port, A.D.; Tung, J.; Wethington, E. and Reid, M.C. (2013) 'Temporal Horizons in Pain Management: Understanding the Perspectives of Physicians, Physical Therapists, and Their Middle-Aged and Older Adult Patients', The Gerontologist 53.5: 850-60

Meier, S. and Sprenger, C. (2010) 'Present-Biased Preferences and Credit Card Borrowing', American Economic Journal: Applied Economics 2: 193-210

Rae, J.M.C.W. (1905) The Sociological Theory of Capital, New York: The Macmillan Co.

Read, D. and Read, N.L. (2004) 'Time Discounting Over the Lifespan', Organizational Behavior and Human Decision Processes 94.1: 22-32

Rubalcava, L.; Teruel, G. and Thomas, D. (2009) 'Investments, Time Preferences and Public Transfers Paid to Women', Economic Development and Cultural Change 57.3: 507-38

Samuelson, P.A. (1937) 'A Note on Measurement of Utility', The Review of Economic Studies 4.2: 155-161

Sozou, P.D. and Seymour, R.M. (2003) 'Augmented Discounting: Interaction Between Ageing and Time-Preference Behavior', Proceedings of the Royal Society of London Series B: Biological Sciences 270.1519: 1047-53

Smith, A. (1776) An Inquiry into the Nature and Causes of the Wealth of Nations, London: W. Strahan and T. Cadell

Steinberg, L.; Graham, S.; O’Brien, L.; Woolard, J.; Cauffman, E. and Banich, M. (2009) 'Age Differences in Future Orientation and Delay Discounting', Child Development 80.1: 2844 
Trostel, P.A. and Taylor, G.A. (2001) 'A Theory of Time Preference', Economic Inquiry 39: 379-95

Vieider, F.M.; Chmura, T. and Martinsson, P. (2012) Risk Attitudes, Development, and Growth: Macroeconomic Evidence from Experiments in 30 Countries, Discussion Papers, WZB Junior Research Group Risk and Development SP II 2012-401, Social Science Research Center Berlin (WZB)

Whelan, R. and McHugh, L.A. (2009) 'Temporal Discounting of Hypothetical Monetary Rewards by Adolescents, Adults, and Older Adults', Psychological Record 59.2 